Erikson, D. (1955). J. gen. Microbiol. 13, 119-126

\title{
Changes in Refractility and Permeability accompanying Germination of Heat-resistant Spores of Micromonospora vulgaris
}

\author{
BY DAGNY ERIKSON \\ Bacteriology Department, University of Aberdeen
}

\begin{abstract}
SUMMARY: Progressive stages in the germination at $60^{\circ}$ of the highly refractile spores of Micromonospora vulgaris were observed by means of phase-contrast microscopy. The development of individual spores was followed in slide cultures. Mass cultures were also prepared in liquid and solid media from spore suspensions in phosphate buffer which had been heated at $100^{\circ}$ for periods of 1-20 min. and 30 min. $-4 \mathrm{hr}$. The liquid cultures derived from heated and unheated spores were sampled at frequent intervals and examined in wet preparations containing dilute toluidine blue. Throughout, loss of refractility preceded germination, which occurred in 1-3 hr. Germinating spores appeared as dense opaque bodies by phase contrast and were then capable of absorbing the dyestuff to which non-germinating spores were impermeable.

Heat activation at $100^{\circ}$ for $1 \mathrm{~min}$. enhanced the initial germination rate within the first $3 \mathrm{hr}$. period. No differences were observed between heated and unheated spores during the processes of germination. Indications of an eccentric 'nucleus' were occasionally found in phase-contrast examination of very lightly stained fixed spores from material heated for short periods, or in electron micrographs of unheated growths. Heating at $100^{\circ}$ for the shorter periods (1-10 min.) resulted in a higher proportion of the spores becoming darkened than was the case with the longer exposures. Artificial darkening of the spores in the manner successfully used for eubacterial spores was not accomplished. Sectored colonies-the sectors showing loss of aerial mycelium and impaired viability - frequently developed from spores which had been subjected for more than $1 \mathrm{hr}$. to a temperature of $100^{\circ}$.
\end{abstract}

Intense refractility is an outstanding property possessed by the spores of organisms of the genus Micromonospora in general (Erikson, 1949) and especially by the thermophilic species (see original description by Tsiklinsky, 1899, under the name of Thermoactinomyces vulgaris). Impermeability to ordinary bacteriological stains is to a certain extent also a character of the mature spores of Micromonospora vulgaris, although as pointed out by Erikson (1952) they show up well with Gray's spore stain. In phase-contrast preparations the spores appear as clear or as dense round bodies according to the age of the specimen and the technique used in preparing it for microscopical examination. This study follows the germination of individual spores without previous heat treatment, and of spores in mass cultures subjected to different types of heat treatment.

\section{METHODS}

Slide cultures were prepared by placing a drop of molten CPS agar medium (for details of composition see Erikson, 1952) in a hollow-ground slide, seeding it with a dilute suspension of spores, and sealing with a coverslip. Suitable 
fields with spores well dispersed were charted, their positions noted by means of the vernier readings of the mechanical stage, and photographed. The complete microscope stage, which was movable, was placed for incubation at $60^{\circ}$ in a moist chamber. At definite intervals of time the stage was taken out of the incubator, replaced on the microscope, and the field under examination quickly found and photographed; after which the stage was returned to the incubator with the least possible loss of time.

For the heat treatment tests spores were harvested as follows: the 2-day growth on cellophan over a plate of CPS medium was washed off with distilled water, lightly shaken, filtered through sterile glass wool, centrifuged and resuspended in $\mathrm{M} / 75$ phosphate buffer $(\mathrm{pH} \mathrm{7 \cdot 0)}$ according to methods described by Erikson \& Webley (1953) and by Webley (1954). Since it was desired to have as many spores as possible under observation simultaneously, and as the proportion of viable spores under these artificial conditions was low, no attempt was made to dilute the suspensions or to obtain approximate counts as was done previously (Erikson, 1952). Each plate yielded c. $2 \mathrm{ml}$. dense suspension which was placed for heating in a screw-capped bottle $(5 \times 2 \mathrm{~cm}$.). Heating was carried out for varying periods in a steamer at $100^{\circ}$, time being allowed for the internal temperature of the bottles to reach $100^{\circ}$. When the bottles were taken out of the steamer they were immediately plunged into ice. Samples of the heated suspensions were placed in small Durham tubes, centrifuged, the supernatant liquid removed and the spores resuspended in nutrient CPS broth or starch + casein hydrolysate medium (Erikson, 1952). Unheated controls were treated similarly. Incubation was at $60^{\circ}$.

A sample droplet from each heated and control phosphate buffer suspension was used for inoculating the surface of a cellophan circle placed instead of a coverslip over the medium in the well of a hollow-ground slide as above. The series of slide cultures in each experiment were incubated in individual sterile slide boxes containing moistened absorbent cotton-wool and fitted with tight lids. Observations on the development of the heated spores were made at hourly intervals by direct microscopical examination of the growths on the cellophan circles. Representative circles were kept for permanent reference by being mounted like sections on slides (Erikson, 1954). Duplicate Durham tubes containing the liquid cultures were removed from the incubator at the same intervals $(2,3,4,18 \mathrm{hr}$.) as the cellophan slide cultures. Neutral formalin $(5 \%, \mathrm{v} / \mathrm{v})$ was added to the liquid cultures as fixative.

In this way it was possible to compare simultaneously the development in liquids and on solid surfaces of spores similarly treated before germination. Phase-contrast microscopy was used throughout, employing a Watson 'Bactil' microscope with Watson phase-contrast accessories for the greater part of the study. A Cook, Troughton and Sims microscope with movable stage and phasecontrast substage was used for the examination of the unheated individual spores in slide cultures sealed with cover-glasses.

It was found that those spores which had lost their refractility and which in wet preparations appeared dense by phase-contrast microscopy, were also permeable to a dilute ethanolic solution of toluidine blue $(0.005-0.01 \%, \mathrm{w} / \mathrm{v})$. 
By the simple means of adding one drop of the dye solution to the drop of distilled water in which sample cells from liquid cultures were mounted, a convenient and rapid method was available for checking the validity of the observations made on surface growths. Brilliant preparations could be made by the combined use of phase-contrast microscopy and such a light degree of staining (see $\mathrm{Pl}$. 4, fig. 17).

Detailed tests were made on three different strains (H, B2, D3) of Micromonospora vulgaris, exposing the spore suspensions to periods of $1,5,10,15$ and $20 \mathrm{~min}$. at $100^{\circ}$. Specimens of all the 7 strains in stock were also subjected to more drastic heating: from $30 \mathrm{~min}$. to $4 \mathrm{hr}$. at $100^{\circ}$. In these instances very dense suspensions were used, and after being heated the material was washed (centrifuge), and resuspended in liquid medium or diluted and plated in solid medium. Random samplings were made from this material in order to see whether any impairment of the mature growth occurred.

\section{RESULTS}

Normal spore germination

The mature spores taken from a 2-day culture (strain B2) when seeded on to the surface of a slide culture and sealed with a cover-slip appeared almost always clear (Pl. 1, fig. 1). With careful examination it was usually possible, however, to find certain individuals whose bodies had darkened naturally. Two such dense spores can be seen within the rectangle drawn round six spores in Pl. 1, fig. 1. It will be noted that of the twenty-five spores dispersed outside the rectangle, no others had darkened before incubation. Before any result was noted or photograph taken, the reality of the phenomenon of darkening was ascertained by focusing upwards and downwards to make certain that the appearance was not due to a difference in planes on the part of the minute spores. After doing this repeatedly the viewer could have no doubt whether or not certain spores within a restricted field were clear or dense (see Pl. 1, fig. 2, an enlargement of the area contained within the rectangle in $\mathbf{P l}$. 1, fig. 1). It was also possible by taking cover-slip impression preparations of mature growth on plates to examine much larger fields and there determine the great preponderance of clear spores (see Pl. 3, fig. 15).

After incubation for $1 \mathrm{hr}$. at $60^{\circ}$ there was commonly a perceptible darkening of several spores within any given field. Thus in Pl. 1, fig. 4, two more spores had darkened within the rectangular area, while at least another two could be seen outside the rectangle in Pl. 1, fig. 3. A gradual progressive darkening of two or three more spores continued, and after incubation for $3 \mathrm{hr}$. one of the spores which had been conspicuously refractile before, and which had darkened within the first hour after incubation, had put out a short germ-tube (Pl. 1, fig. 5). It was noteworthy that neither of the two spores within the rectangle which had been dark at the beginning of the experiment showed any further growth. Indeed, by comparison with the germinating spore (Pl. 1, fig. 4; Pl. 2, fig. 6) they had already begun to diminish in volume and appeared to be undergoing the first stages of degeneration. 
After incubation for $4 \mathrm{hr}$. the germinating spore had produced a relatively long filament at an angle from the germ-tube (Pl. 2, fig. 8). The diameter of this filament appeared at this stage uneven along its length, due in part to disorientation as the result of meeting a spore and also to the constriction remaining at the point of origin from the germ-tube. Both the constriction and the pointed bud-like growing point are characteristic features of actinomycetes in general. The boundary lines of the rectangle containing the spores under examination were altered at this stage (Pl. 2, fig. 7 ) in order to include the full length of the young filament in the photograph. Unfortunately, the further development of this particular spore could not be followed because of the partial drying up of the specimen.

The next stage of early mycelial branching, after incubation for $6 \mathrm{hr}$, was photographed (Pl. 2, fig. 9) from the growth of another spore outside the rectangle, which had developed simultaneously and part of whose initial filament can be seen in the top right-hand corner of Pl. 2, fig. 7. The germination of this and other spores in the preparation was like that already followed. The $6 \mathrm{hr}$. growth shown in Pl. 2, fig. 9, developed after incubation for $24 \mathrm{hr}$. into the typical small mycelium shown in Pl. 2, fig. 10.

\section{Germination of spores subjected to heating for 1-20 $\min$. at $100^{\circ}$}

The effect of heat activation on Micromonospora vulgaris spores was earlier found to be optimum when dilute broth or sucrose suspensions were exposed to a temperature of $85^{\circ}$ for $15 \mathrm{~min}$. (Erikson, 1952). In the present work as a result of the use of phosphate buffer suspensions prepared as described by Webley (1954), it was found that in the early stages of germination the spores were responsive to a higher range of temperatures. An examination of the growths obtained on the cellophan slide cultures revealed that the highest initial percentage of germinated spores was found $3 \mathrm{hr}$. after incubation in the set which had been pre-heated at $100^{\circ}$ for $1 \mathrm{~min}$., namely : $9 \%$ as compared with $5 \%$ in the case of the unheated control, and $7,6,4$ and $3 \%$ in the case of the material which had been pre-heated at $100^{\circ}$ for $5,10,15$ and 20 min., respectively. After incubation for $5 \mathrm{hr}$. there was little to choose between the three sets pre-heated for 1, 5, or $10 \mathrm{~min}$; ; all showed a higher proportion of germinations than the others. Then after $7 \mathrm{hr}$. there was a slight increase in numbers germinated in the set heated for $5 \mathrm{~min}$., as well as a difference in the average dimensions of the young growing filaments. This difference in length was most noticeable in the series that had been heated for longer periods. Thus filaments 15-20 $\mu$. long were conspicuous in the 10, 15 and $20 \mathrm{~min}$. series, whereas lengths of $1-10 \mu$. were more general in the $100^{\circ}$ for $1 \mathrm{~min}$. set, as well as in the unheated control. An intermediate length of 5-15 $\mu$. was found in the $100^{\circ}$ for $5 \mathrm{~min}$. set, where there were the greatest number of germinations. The values quoted were based on the average of ten readings for each slide. After incubation for $9 \mathrm{hr}$. small mycelia could be found in most slides; thereafter, the growth was too crowded for further observations to be made. 
Examination of the cellophan growths by means of the $4 \mathrm{~mm}$. dry objective with the phase-contrast system revealed no differences between the heated and unheated spores with respect to their germination, apart from the acceleration or retardation already mentioned. It was not possible to distinguish clearly the darkening of the spores because of the high degree of refractility of the cellophan itself. For this purpose the companion set of liquid cultures (sown with identical suspensions and incubated for the same periods of time) was used and several wet preparations were made from each tube with and without the addition of toluidine blue (see Methods). Similar results were found with unstained or stained material: all germinated spores, heated or unheated, exhibited a loss of refractility accompanied by an increase in permeability to dye. Owing to the tendency of the spores to show Brownian motion it was often found advisable to dry the fixed cells on the coverslip before mounting. In this way the differences in density between germinated and non-germinating spores lying in the same plane could readily be distinguished (Pl. 3, fig. 13). It was often possible to find numbers of darkened spores which showed no signs of germ-tubes, either because the specimen had been removed at an early stage in the course of the incubation (Pl. 3, fig. 12), or because the heat treatment (especially for 1-10 min.) had resulted in a preliminary 'quickening' of the spores followed by degeneration and death of large numbers of them (Pl. 3, fig. 16). The contrast between a mass of darkly staining heated spores (Pl. 3, fig. 16) and the clear refractile unheated spores (Pl. 3, fig. 15) was not always as clear-cut as in these photographs. Thus, clear unchanged spores were often found in heated material whether the period of heat treatment had been of short (Pl. 3, fig. 11) or of moderate (Pl. 3, fig. 14) duration.

\section{Germination of spores subjected to heating for $30 \mathrm{~min}$. to $4 \mathrm{hr}$.}

In general, these longer periods of heating resulted in a higher proportion of the spores remaining unchanged. This is well seen in Pl. 4, fig. 17, where the approximately even distribution of clear and dense spores is visible over a broad field. But here again the germinated spores (around which small rectangles have been drawn) will be found stained with toluidine blue. This illustration is an example of the higher limits of thermotolerance $(30 \mathrm{~min}$. at $100^{\circ}$ ), beyond which normal growth in microculture rarely occurred within the first $12 \mathrm{hr}$. of incubation. Thus Pl. 4, fig. 18, depicts a $24 \mathrm{hr}$. growth of material which had been heated for $60 \mathrm{~min}$. at $100^{\circ}$. The tendency towards rapid filamentous elongation on the part of those spores which did survive prolonged heating was very noticeable in the sets exposed to $100^{\circ}$ for $30-40 \mathrm{~min}$.; a typical example can be seen in that portion of a main filament which extends diagonally across the entire field in Pl. 4, fig. I7.

When very dense suspensions of all the stock strains were subjected to drastic heating (see Methods), it was found that five strains (D 3, B 2, H, D, M) were capable of producing typical surface growth within $24 \mathrm{hr}$. at $60^{\circ}$ after being heated at $100^{\circ}$ for periods of $40-100 \mathrm{~min}$. In the case of strain $\mathrm{H}$ 
survivors were obtained after heating for $4 \mathrm{hr}$. at $100^{\circ}$. Random samplings during the early stages of growth revealed no perceptible differences as regards the aspect of the germinating spores, but when the drastically heated suspensions were plated it was often found that there were sectors devoid of aerial mycelium in the few giant colonies produced (Pl. 4, fig. 22). It was rarely possible to subculture from these sectors, such growths as ensued being of a transitory vegetative nature.

\section{Internal structure of spores}

Occasionally during the examination of living slide cultures, and more often in preparations of fixed and very lightly stained cells, amidst the general mass of homogeneous spores certain individuals were noticeable in that they seemed to have an eccentric 'nucleus' (Pl. 3, figs. 12, 16; Pl. 4, fig. 18). Some confirmation of this aspect was obtained by electron microscopy of normal unheated growths. Thus the immature spore attached to the parent stalk was found to be dense and impermeable (Pl. 4, fig. 19), while the mature spores varied from density (see two spores in top left-hand corner and centre of Pl. 4, fig. 20) to partial density (see bottom and right-hand spores in Pl. 4, fig. 20; also enlargement in $\mathrm{Pl}$. 4, fig. 21).

\section{Artificial darkening of spores}

When suspensions of Micromonospora vulgaris spores were mixed with adenosine according to the methods used by Pulvertaft \& Haynes (1951) with eubacterial spores, no artificial darkening of the spores occurred. Similarly, incubation of the spores with L-alanine as described by Powell (1950) for Bacillus subtilis did not cause changes in staining properties or loss of heat resistance in the case of Micromonospora vulgaris. It would therefore appear that the heat-resistant spores of $\boldsymbol{M}$. vulgaris, although resembling eubacterial spores in refractility and relative impermeability, possessed these properties in differing degrees and possibly as the result of different mechanisms. In view of the entirely different mode of growth and of sporogenesis shown by the actinomycete, this is not unexpected.

This work was done by the author as a member of the scientific staff of the Agricultural Research Council. I wish to thank Professor J. Cruickshank, C.B.E., for the hospitality of his department; Dr D. M. Webley of the Macaulay Institute for Soil Research for permission to use the Cook, Troughton and Sims phase-contrast microscope and help with the photographs taken with it; and Miss Mildred Mackay for technical assistance. Mr Gard of the University of Aberdeen kindly took the electron micrographs. 


\section{REFERENCES}

Erikson, D. (1949). The morphology, cytology, and taxonomy of the actinomycetes. Annu. Rev. Microbiol. 3, 23.

Erikson, D. (1952). Temperature/growth relationships of a thermophilic actinomycete, Micromonospora vulgaris. J. gen. Microbiol. 6, 286.

Erikson, D. (1954). Factors promoting cell division in a 'soft' mycelial type of Nocardia: Nocardia turbata n.sp. J. gen. Microbiol. 11, 198.

Erikson, D. \& Webley, D. M. (1953). The respiration of a thermophilic actinomycete, Micromonospora vulgaris. J. gen. Microbiol. 8, 455.

Powell, J. F. (1950). Factors affecting the germination of thick suspensions of Bacillus subtilis spores in L-alanine solution. J. gen. Microbiol. 4, 330.

Pulvertaft, R. J. V. \& Haynes, J. A. (1951). Adenosine and spore germination: phase-contrast studies. J. gen. Microbiol. 5, 657.

Tsikm linsky, P. (1899). Sur les mucédinées thermophiles. Ann. Inst. Pasteur, 13, 500.

WEBLEy, D. M. (1954). The effect of oxygen on the growth and metabolism of the aerobic thermophilic actinomycete Micromonospora vulgaris. J. gen. Microbiol. $11,114$.

\section{EXPLANATION OF PLATES}

Phase-contrast preparations unless stated otherwise.

Plate 1

Fig. 1. Spores of M. vulgaris (strain B2) in slide culture before incubation. ( $\times 1325$.)

Fig. 2. Enlargement of rectangle in fig. $1 .(\times 4635$. $)$

Fig. 3. Same as fig. 1 , after 1 hr. at $60^{\circ}$. Observe darkening of certain spores. $(\times 1325$. $)$

Fig. 4. Enlargement of rectangle in fig. 3. $(\times 4635$.

Fig. 5. Same as fig. 1, after $3 \mathrm{hr}$. at $60^{\circ}$. Note germ-tube issued by central spore. $(\times 1325$. $)$

\section{Plate 2}

Fig. 6. Enlargement of rectangle in fig. 5. $(\times 4635$.

Fig. 7. Same as fig. 1, after $4 \mathrm{hr}$. at $60^{\circ}$. Germ-tube has produced filamentous branch. $(\times$ 1325.)

Fig. 8. Enlargement of rectangle in fig. 7. $(\times 4635$.

Fig. 9. Another field in same specimen after $6 \mathrm{hr}$. at $60^{\circ}$. Beginning of ramification. $(\times 1325$.

Fig. 10. Same as fig. 9 , after $24 \mathrm{hr}$. at $60^{\circ}$. Small mycelium. $(\times 1325$.

\section{Plate: 3}

Fig. 11. Spore suspension of M. vulgaris (strain D3) heated 5 min. at $100^{\circ}$, cultured $18 \mathrm{hr}$. in liquid medium. Note number of clear unchanged spores as well as young growths. $(\times 1920$.

Fig. 12. Spores (strain D3) heated $15 \mathrm{~min}$. at $100^{\circ}$, cultured $5 \mathrm{hr}$. in liquid medium. Dense spores, only one germinated. $(\times 3120$. $)$

Fig. 13. Spores (strain D 3) heated $30 \mathrm{~min}$. at $100^{\circ}$, cultured $18 \mathrm{hr}$. in liquid medium. Of two spores fixed in same plane on coverslip germinating one is dark, non-germinated, one clear. $(\times 3120$. $)$

Fig. 14. Spores (strain D3) heated $20 \mathrm{~min}$. at $100^{\circ}$, cultured $6 \mathrm{hr}$, in liquid medium. Some clear and some dark spores still attached to parent branch; dense spore at top germinated. $(\times 1920$.

Fig. 15. Impression preparation of mature 4-day growth (strain B2) on agar plate. Spores predominantly clear. $(\times \mathbf{2 1 6 0}$. $)$

Fig. 16. Spores (strain D 3) heated $10 \mathrm{~min}$. at $100^{\circ}$, cultured $18 \mathrm{hr}$. in liquid medium. Stained toluidine blue. Young mycelial growth and mass of dense spores. $(\times \mathbf{2 4 0 0}$.) 
Plate 4

Fig. 17. Spores (strain D3) heated $30 \mathrm{~min}$. at $100^{\circ}$, cultured $18 \mathrm{hr}$. in liquid medium. Stained toluidine blue. Both clear and dark spores. Germinating spores (with small rectangles drawn round) always dark. Growing filaments showing marked elongation, the one crossing the field diagonally being only a short portion of the real growth. $(\times 1920$.

Fig. 18. Spores (strain D3) heated for $60 \mathrm{~min}$. at $100^{\circ}$, cultured $24 \mathrm{hr}$. in liquid medium. Stained toluidine blue. Light and dark spores, some of which give indications of internal structure. $(\times \mathbf{2 4 0 0})$

Fig. 19. Immature spore (strain $\mathbf{H}$ ) attached to parent stalk. Spore completely dense. Electron micrograph. $(\times 17,000$.

Fig. 20. Mature spores (strain $\mathrm{H}$ ) from same preparation as in fig. 19. Two spores completely dense, two showing apparent eccentric 'nucleus'. Electron micrograph $(\times 6000$.)

Fig. 21. Enlargement of partially dense spore in fig. 20. $(\times 29,500$. $)$

Fig. 22. Giant colony (strain $\mathbf{H}$ ) with sector devoid of aerial mycelium and small secondary outgrowth. Survivor from spore suspension heated $80 \mathrm{~min}$. at $100^{\circ}$. $(\times 1$.

(Received 21 January 1955) 
Journal of General Microbiology, Vol. 13, No. 1

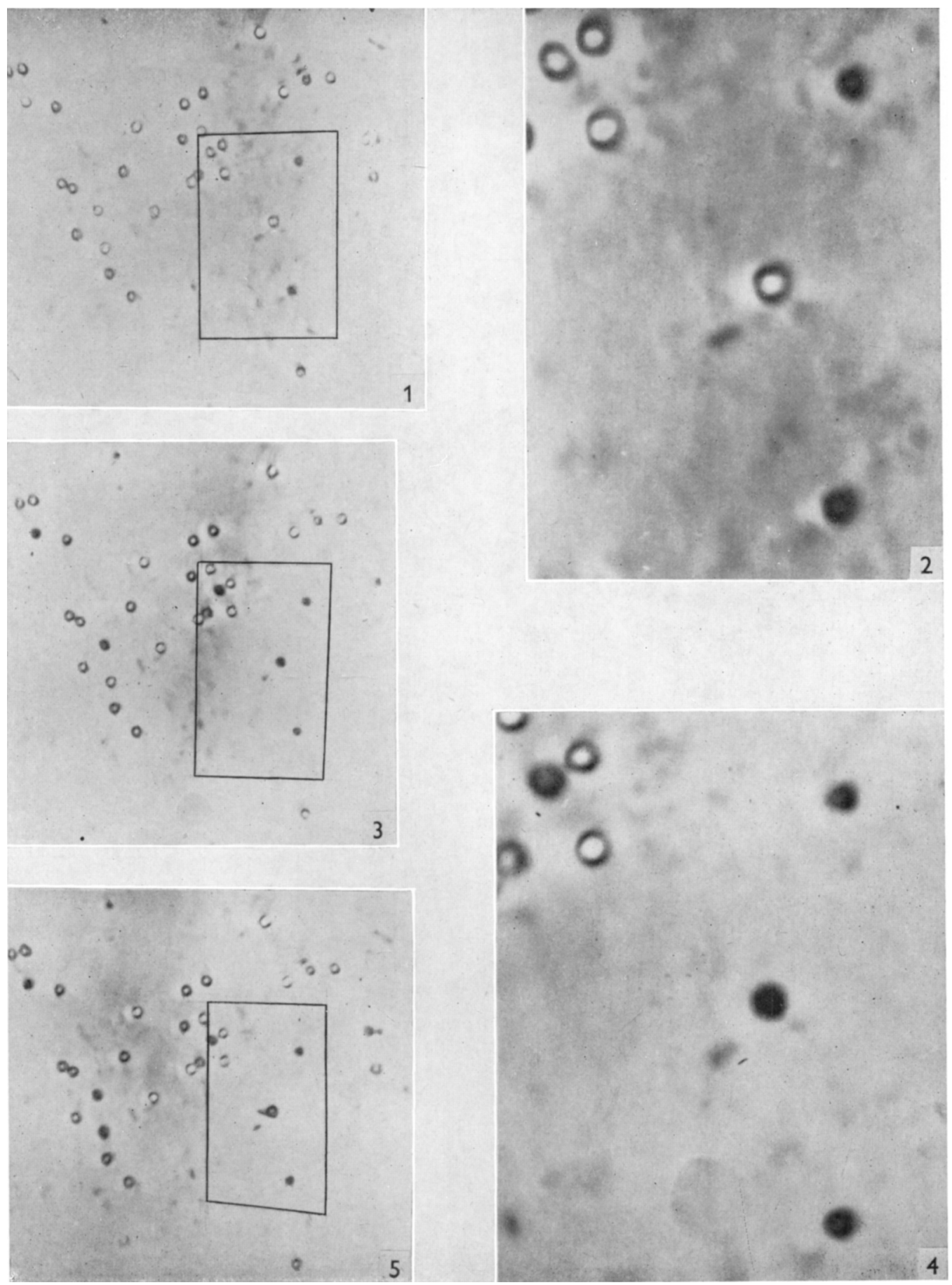

D. Erikson-Germination of spores of $M$. vulgaris. Plate 1 
Journal of General Microbiology, Vol. 13, No. 1
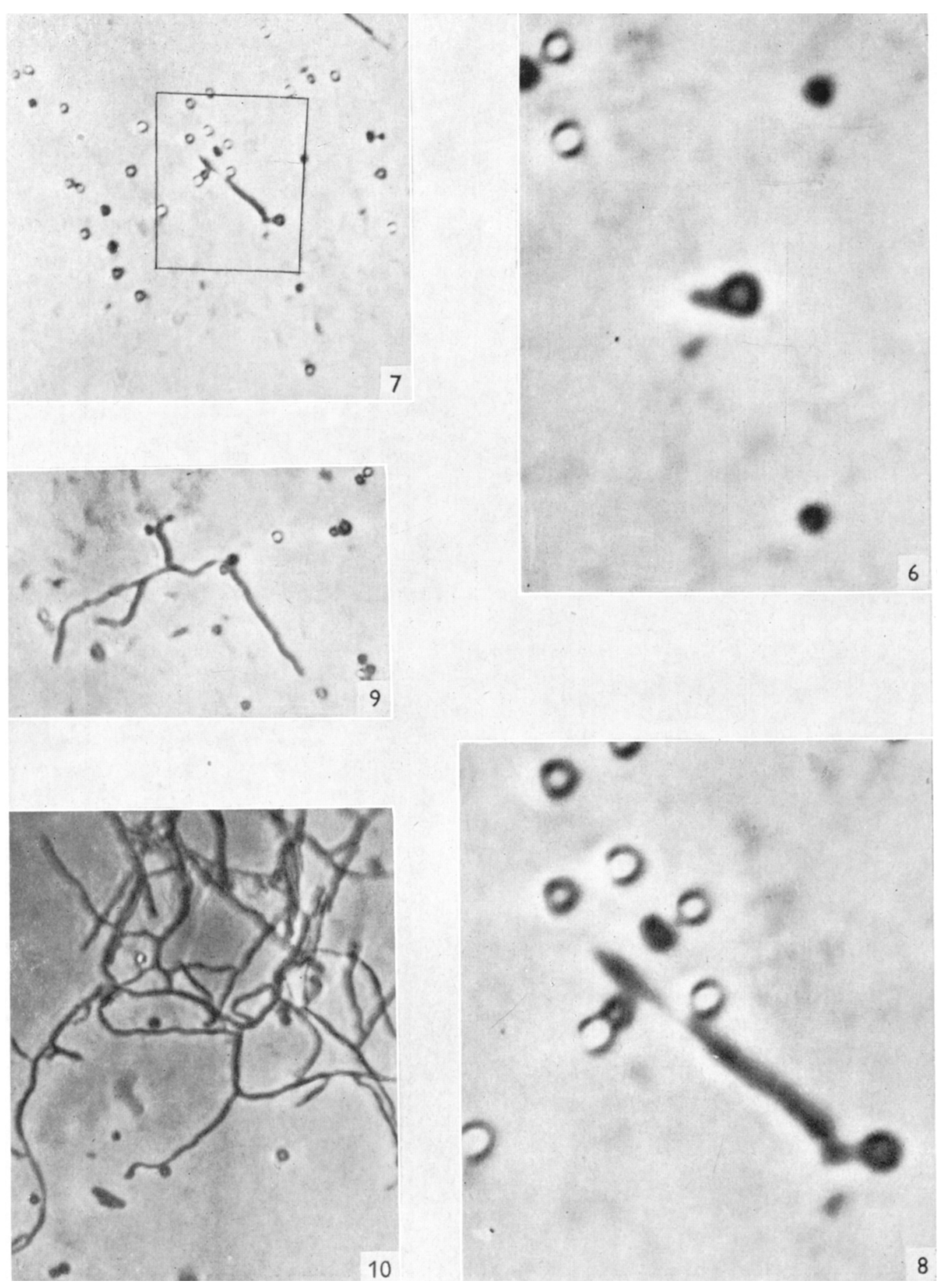

D. Erikson-Germination of spores of M. velgaris. Plate 2 
Journal of General Microbiology, Vol. 13, No. 1
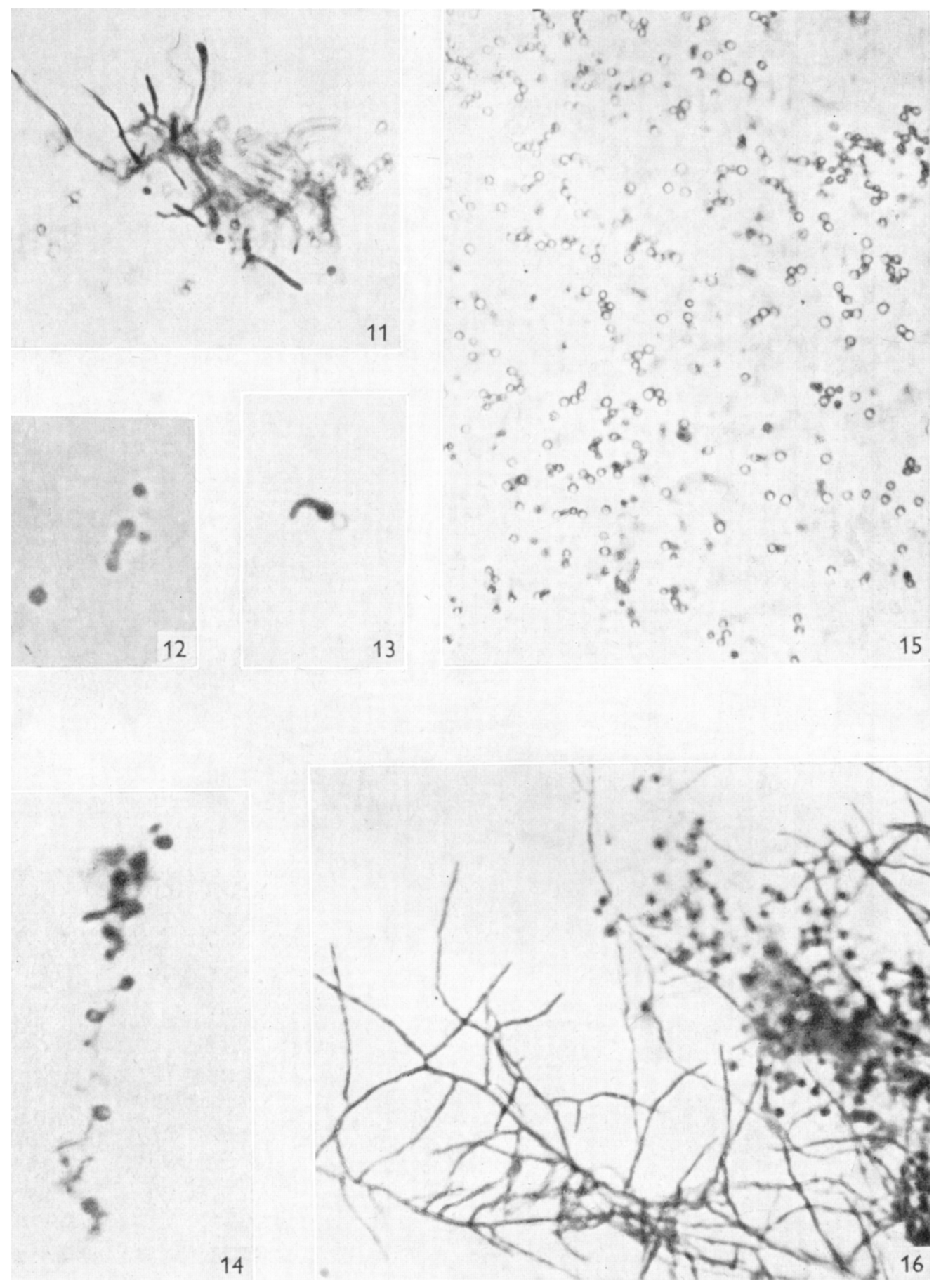

D. Erikson-Germination of spores of M. vulgaris. Plate 3 
Journal of General Microbiology, Vol. 13, No. 1
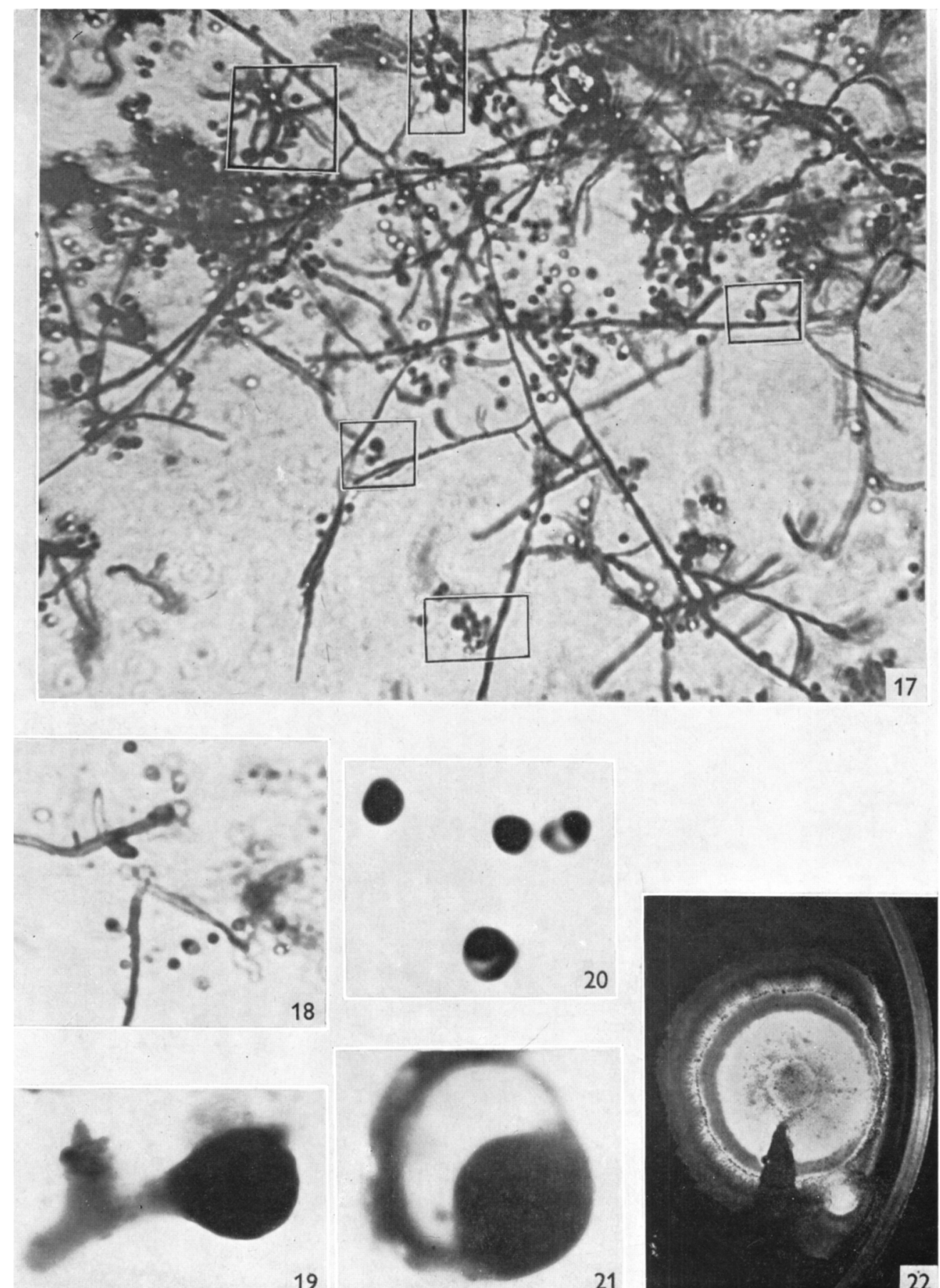

19

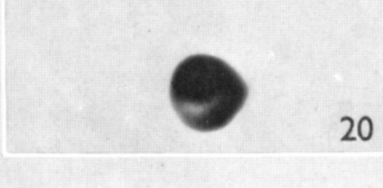

20

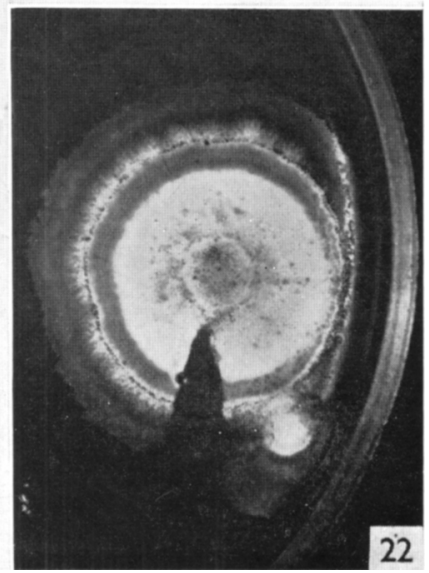

D. Erikson-Germination of spores of M. relgaris. Plate 4 